\title{
Herd-level risk factors for lameness in freestall farms in the northeastern United States and California
}

\author{
N. Chapinal, ${ }^{*}$ A. K. Barrientos, ${ }^{*}$ M. A. G. von Keyserlingk, ${ }^{*}$ E. Galo,† and D. M. Weary ${ }^{* 1}$ \\ *Animal Welfare Program, University of British Columbia, Vancouver, BC, Canada V6T 1 Z4 \\ †Novus International Inc., St. Charles, MO 63304
}

\begin{abstract}
The objective was to investigate the association between herd-level management and facility design factors and the prevalence of lameness in high-producing dairy cows in freestall herds in the northeastern United States (NE; Vermont, New York, Pennsylvania) and California (CA). Housing and management measures such as pen space, stall design, bedding type, and milking routine were collected for the high-producing pen in 40 farms in NE and 39 farms in CA. All cows in the pen were gait scored using a 1-to-5 scale and classified as clinically lame (score $\geq 3$ ) or severely lame (score $\geq 4$ ). Measures associated with the (logit-transformed) proportion of clinically or severely lame cows at the univariable level were submitted to multivariable general linear models. In NE, lameness increased on farms that used sawdust bedding [odds ratio $(\mathrm{OR})=$ $1.71 ; 95 \%$ confidence interval $(\mathrm{CI})=1.06-2.76]$ and decreased with herd size $(\mathrm{OR}=0.94 ; \mathrm{CI}=0.90-0.97$, for a 100-cow increase), use of deep bedding $(\mathrm{OR}=0.48$; $\mathrm{CI}=0.29-0.79)$, and access to pasture $(\mathrm{OR}=0.52$; CI $=0.32-0.85)$. The multivariable model included herd size, access to pasture, and provision of deep bedding, and explained $50 \%$ of the variation in clinical lameness. Severe lameness increased with the percentage of stalls with fecal contamination $(\mathrm{OR}=1.15$; $\mathrm{CI}=$ $1.06-1.25$, for a $10 \%$ increase) and with use of sawdust bedding $(\mathrm{OR}=2.13 ; \mathrm{CI}=1.31-3.47)$, and decreased with use of deep bedding ( $\mathrm{OR}=0.31$; $\mathrm{CI}=0.19-0.50)$, sand bedding $(\mathrm{OR}=0.32 ; \mathrm{CI}=0.19-0.53)$, herd size $(\mathrm{OR}=0.93 ; \mathrm{CI}=-0.89-0.97$, for a $100-$ cow increase $)$, and rearing replacement heifers on site $(\mathrm{OR}=0.57$; $\mathrm{CI}=0.32-0.99)$. The multivariable model included deep bedding and herd size, and explained $59 \%$ of the variation of severe lameness. In CA, clinical lameness increased with the percentage of stalls containing fecal contamination $(\mathrm{OR}=1.15 ; \mathrm{CI}=1.05-1.26$, for a $10 \%$ increase), and decreased with herd size $(\mathrm{OR}=0.96$;
\end{abstract}

Received July 13, 2012.

Accepted September 14, 2012.

${ }^{1}$ Corresponding author: danweary@mail.ubc.ca
$\mathrm{CI}=0.94-0.99$, for a 100-cow increase), presence of rubber in the alley to the milking parlor $(\mathrm{OR}=0.46$; $\mathrm{CI}=0.28-0.76)$, distance of the neck rail from the rear curb $(\mathrm{OR}=0.97$; $\mathrm{CI}=0.95-0.99$, for a 1 -cm increase $)$, water space per cow $(\mathrm{OR}=0.92$; $\mathrm{CI}=0.85-0.99$, for a 1-cm increase), and increased frequency of footbaths per week $(\mathrm{OR}=0.90$; CI $=081-0.99$, for a 1 -unit increase). The multivariable model included herd size, percentage of stalls containing fecal contamination, and presence of rubber in the alley to the milking parlor, and explained $44 \%$ of the variation of clinical lameness. Severe lameness increased with the percentage of stalls containing fecal contamination $(\mathrm{OR}=1.23$; CI $=1.06-1.42$, for a $10 \%$ increase) and decreased with frequency of manure removal in the pen per day (OR $=0.72 ; \mathrm{CI}=0.53-0.97$, for a 1 -unit increase). The final model included both variables and explained $28 \%$ of the variation in severe lameness. In conclusion, changes in housing and management may help decrease the prevalence of lameness on dairy farms, but key risk factors vary across regions.

Key words: deep bedding, gait, management, stall design

\section{INTRODUCTION}

Lameness is one of the most important welfare and production problems in modern dairy herds. The current trend in the dairy industry is to house cows in freestalls, but research suggests that freestall housing increases the risk for lameness relative to other housing systems, including tie stalls and straw yards (Cook, 2003; Sogstad et al., 2005). On-farm surveys in North America have reported an average prevalence of clinical lameness of 20 to $55 \%$ for freestall-housed herds, with much variability across farms (Espejo et al., 2006; Ito et al., 2010). This variation in prevalence may be due, in part, to differences in how these farms are designed and managed.

Few studies have investigated the complex interaction between lameness and herd-level risk factors for modern freestall herds. Factors associated with lameness in previous studies include stall features (Espejo and 
Endres, 2007; Dippel et al., 2009), lying surface (Cook, 2003; Espejo et al., 2006; Ito et al., 2010), time spent away from the pen for milking (Espejo and Endres, 2007), the use of automatic alley scrapers (Barker et al., 2007), and hoof trimming practices (Amory et al., 2006; Espejo and Endres, 2007). Some of these differences across studies can be explained by geographical differences in facility design and management, resulting from different availability of resources for facility construction and popular opinions of best practices in the area.

We recently completed a large, cross-farm study examining herd differences in the prevalence of lameness in 2 regions of the United States with different environmental conditions and different traditions of barn design and management: the northeastern United States (Vermont, New York, and Pennsylvania; NE) and California (CA). As reported in our companion paper (von Keyserlingk et al., 2012), the prevalence of clinical lameness averaged $55 \%$ in $\mathrm{NE}$ and $31 \%$ in $\mathrm{CA}$, but with a large variability within region. When only severely lame cows were considered, the estimated prevalence was 8 and $4 \%$ for NE and CA, respectively. The objective of the current paper was to investigate the association between herd-level management and facility design factors and the prevalence of lameness in high-producing dairy cows in freestall herds in these 2 regions.

\section{MATERIALS AND METHODS}

\section{Farm Selection and Visits}

As described by von Keyserlingk et al. (2012), 40 farms in NE (New York $\mathrm{n}=28$, Pennsylvania $\mathrm{n}=8$, and Vermont $\mathrm{n}=4$ ) and 39 farms in CA were selected within the C.O.W.S. program, a partnership between The University of British Columbia and Novus International Inc. (http://www.novusint.com/en/MarketSegments/Dairy/COWS) for this cross-sectional study. Consulting nutritionists ( $\mathrm{n}=8$ in $\mathrm{CA} ; \mathrm{n}=24$ in NE) were asked to randomly select farms from among their lists of clients, considering 2 inclusion criteria: freestall housing and provision of a TMR. All methods used to collect data were approved by the University of British Columbia's Animal Care Committee, which follows the standards outlined by the CCAC (2009).

Farms were visited from March to May 2010 in CA and from July to October 2010 in NE. Each farm was visited twice, with approximately 3 to 5 d between visits. The same 2 trained observers performed all animal and facility-based measures (Table 1) on all farms in each of the 2 regions. One group of high-producing and primarily multiparous cows was assessed on each farm; this high-producing group was identified by the producer.

\section{Lameness Assessment}

All cows housed in the assessment group were gait scored as they exited the parlor using a 5-point Numerical Rating System (NRS), where $1=$ sound and $5=$ severely lame (Flower and Weary, 2006; Chapinal et al., 2009). Cows with NRS $\geq 3$ were considered clinically lame, and cows with NRS $\geq 4$ were considered severely lame. The proportion of clinically and severely lame cows was calculated for each farm.

\section{Management and Facility Design Measures}

Management and facility design measures for the herd and the assessment pen were collected using direct observation of environment and management, an interview with the herd manager during the farm visits, bedding samples, and compilation of herd records. Because of differences in management and facility design, some of the variables considered differed between regions (Table 1).

General Management. General herd and management factors included herd size (obtained from farm records), barn age (estimated by the herd manager), rearing of replacement heifers on site, and access to pasture during the dry period (NE) or to the exercise corral (CA).

Pen Space and Flooring. Variables such as pen space/cow, flooring, and method of manure removal were assessed in the high-producing assessment pen. The overall pen area available $\left(\mathrm{m}^{2}\right)$, calculated as the total length $\times$ width of the pen (i.e., including stalls, alleys, and crossovers), was divided by the number of cows housed in the assessed pen to determine the space per cow. Most of the farms had concrete floors (except for 3 in NE with rubber). Therefore, the only floor variable considered was whether there was rubber in at least part of the pen. The alley was considered dirty if manure evenly covered the floor at a depth of at least $2 \mathrm{~cm}$. In NE, manure was removed either continuously (or at high frequency) using an automatic scraper or just a few times per day using other methods, such as flushing or a skid steer. Therefore, a dichotomous variable was created for the presence of automatic scraper versus other methods with a lower frequency of manure removal. In CA, manure removal was accomplished several times per day by flushing, skid steer, or a combination of both. Given the available variation, the frequency of manure removal per day was considered in the analysis. 
Table 1. Herd-level predictors of interest considered in the univariable analysis for each region: northeastern United States (NE) or California (CA)

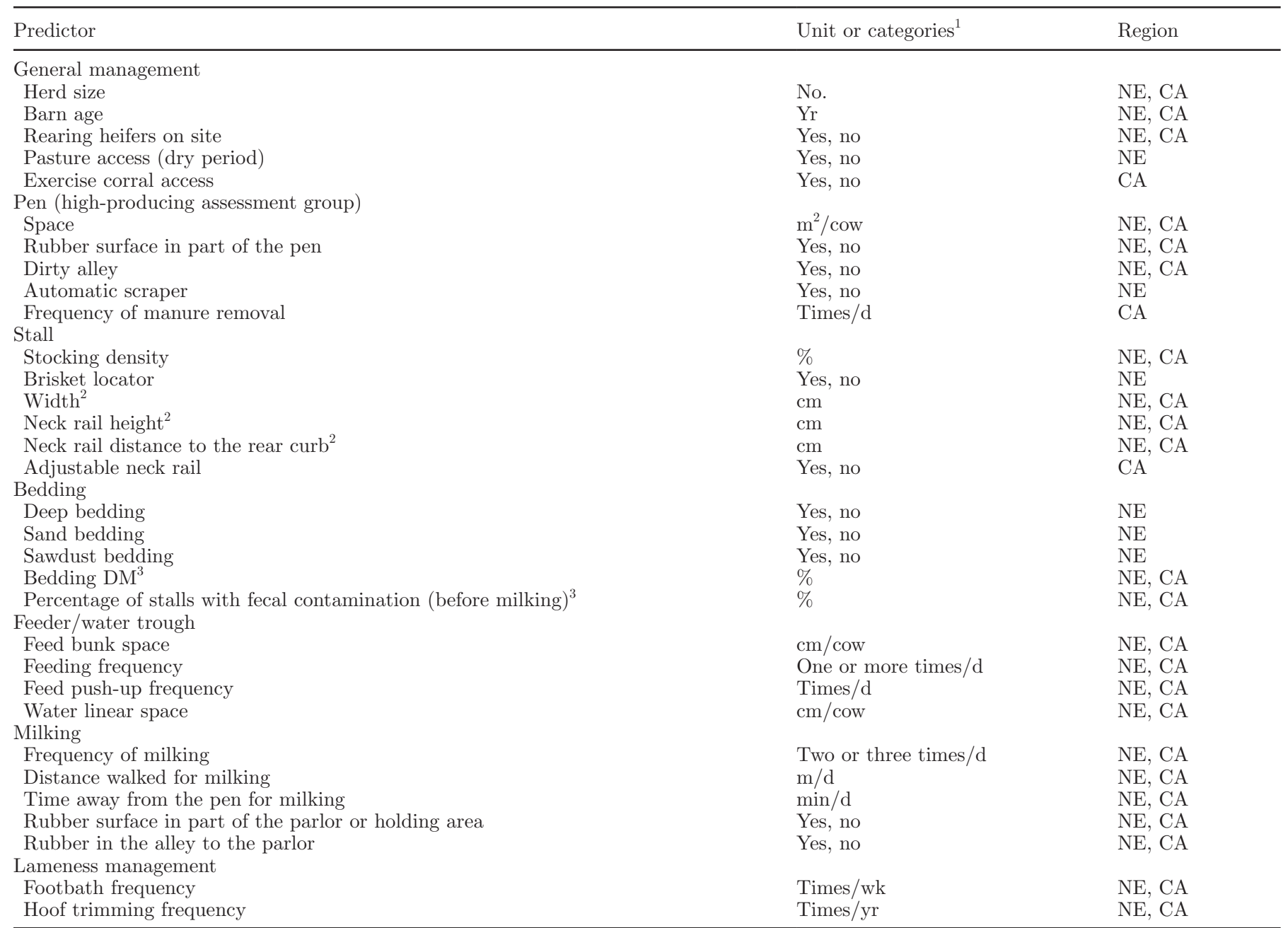

${ }^{1}$ Units and categories are shown for continuous and categorical variables, respectively.

${ }^{2}$ Three to 7 stalls/pen.

${ }^{3}$ Ten stalls/pen.

Stall Stocking Density and Stall Design. Stall stocking density was calculated as the number of cows per available stalls (i.e., stalls with visible barriers preventing cows from lying down were excluded) multiplied by 100. Stall dimensions were measured on (mean $\pm \mathrm{SD}$ ) $4 \pm 1$ stalls per pen (range $=3$ to 7 stalls, depending on the uniformity of the stall design within the pen) and included width, neck rail position (calculated as the horizontal distance between the rear edge of the neck rail and the rear curb), and neck rail height from bedding. These measurements were averaged to obtain 1 value per farm. Total stall length and stall length from the rear curb to the brisket locator were also measured. However, the effective stall length for the cow depends on factors that affect the lunge space, such as the presence and position of the brisket locator, and whether the stalls are in a single row (facing a wall or feed alley) or double row (2 stalls, head-to-head). Due to the large variability in those factors, both within and between farms, it was not possible to develop a definition of stall length that was objective and consistent across farms. Therefore, stall length was not considered in the analysis. Neck rail type (i.e., stationary or adjustable in $\mathrm{CA}$; all neck rails were stationary in NE) and presence of brisket locator (no farms in CA had brisket locators) was also recorded.

Bedding Type and Quality. In CA, all farms had deep-bedded stalls with manure solids except for 4 farms that used sand, and therefore, these variables were not considered. The NE farms showed more variability in the stall base and bedding material. Dichotomous variables were created for deep bedding (the stall 
base was not exposed by digging at least $10 \mathrm{~cm}$ into the bedding compared with smaller amounts of bedding placed onto mattress, concrete, rubber mat, and so on) and the most frequent bedding materials - sand and sawdust. Bedding samples were collected from 10 systematically selected stalls per pen (e.g., if a pen had 100 stalls, every 10th stall was sampled). Samples of approximately $50 \mathrm{~mL}$ were taken from the back onethird of each stall and pooled into one sample per farm; these samples were taken on each visit to avoid bias due to addition of fresh bedding. The percentage DM of the bedding was analyzed at Rock River Laboratory West Inc. (Visalia, CA) for CA farms, and at Dairy One Inc. (Ithaca, NY) for NE farms. The same stalls were also assessed for fecal contamination and classified as either as clean and dry or as containing fecal contamination. The percentage of stalls with fecal contamination was calculated for each farm.

Feeder/Water Trough. Feed bunk and water linear space was measured and divided by the number of cows in the assessed pen to calculate space per cow. Feeding practices, such as frequency of feed delivery and pushups, were also recorded.

Milking. The daily total time that cows were away from the pen for milking was calculated as the time (min) since cows left the assessment pen until the moment when all cows returned to the pen (assessed during 1 milking), multiplied by milking frequency per day. The distance between the assessment pen and the milking parlor was recorded and multiplied by 2 times the milking frequency to calculate the total mandatory distance that cows walked per day due to milking.

Lameness Management. The number of times each cow was hoof trimmed per year and the frequency of footbath per week were recorded. The type of the footbath used was not recorded.

\section{Data Analysis}

Statistical analyses were performed with SAS (version 9.2, 2003; SAS Institute Inc., Cary, NC), considering the herd as the experimental unit. The 2 regions were analyzed separately because of large differences in management and facility design. The outcomes of interest were proportion of high-producing cows with clinical lameness and with severe lameness. A logittransformation with a bias correction factor of 0.25 (Cox and Snell, 1970) was applied to meet the assumptions of normality and homogeneity of variance and to ensure that estimates and CI were correctly calculated. If a linear model is applied directly to proportions, the estimate of the means and CI could fall outside the range of values between 0 and 1 . For instance, the lower CI limit is likely to be negative when the response rate is low. Univariable analyses were first performed to assess the association between the outcome variables and each of the predictors (PROC GLM). Only categorical predictors with at least 6 farms per category were considered. Linearity between continuous predictors and outcome variables was assessed graphically and by testing the quadratic term in the model. Predictors with a univariable association of $P \leq 0.05$ were submitted to a multivariable model (PROC GLM), controlling for the proportion of primiparous cows in the assessment pen. Correlations between the predictors were calculated to avoid submitting highly correlated variables $(|\mathrm{r}|>0.70)$ to the same model. When 2 predictors were highly correlated, the predictor with the strongest univariable association (largest $\mathrm{R}^{2}$ ) was selected. Moreover, variance inflation factors were calculated after each model to confirm lack of multicollinearity. Models were built by manual stepwise selection. First, predictors were removed from the final model if $P>0.05$ through manual backward elimination. If the removal of a variable changed the parameter estimate of any of the remaining predictors by $>30 \%$ on the logit scale, the eliminated variable was retained as a confounder regardless of its $P$-value (Dohoo et al., 2009). In a second step, eliminated predictors were reentered in the model one by one and retained if $P \leq 0.05$. Two-way interactions between the predictors that remained in the final model were tested and retained if $P \leq 0.05$. Residuals were examined after each model to verify normality and homogeneity of variance. Outliers, high leverage points, and observations with an undue influence in the model were examined using residuals, leverage values and Cook's distances. Parameter estimates were back transformed and results are presented as odds ratios (OR) and 95\% CI. The OR expresses how a herd-level predictor affects the odds of experiencing clinical or severe lameness in a particular herd.

\section{RESULTS}

\section{Northeastern United States}

At the univariable level (Table 2), clinical lameness increased with sawdust bedding and decreased with herd size, deep bedding, and access to pasture. Use of deep bedding was correlated with access to pasture $(\mathrm{r}=$ $0.47 ; P=0.003)$ and acted as a confounder for pasture in the final model (when deep bedding was removed from the model, the absolute value of the parameter estimate for pasture increased by $65 \%$ ). Use of sawdust bedding was correlated with both deep bedding $(\mathrm{r}=$ $-0.41 ; P=0.01)$ and herd size $(\mathrm{r}=-0.35 ; P=0.03)$ and was not retained in the final model containing herd size. After controlling for the confounding effect of deep 
Table 2. Univariable associations of the logit-transformed proportion of clinical and severe lameness with herd-level factors in the northeastern United States $\left(\mathrm{n}=40\right.$ and 39 farms for clinical and severe lameness, respectively) ${ }^{1}$

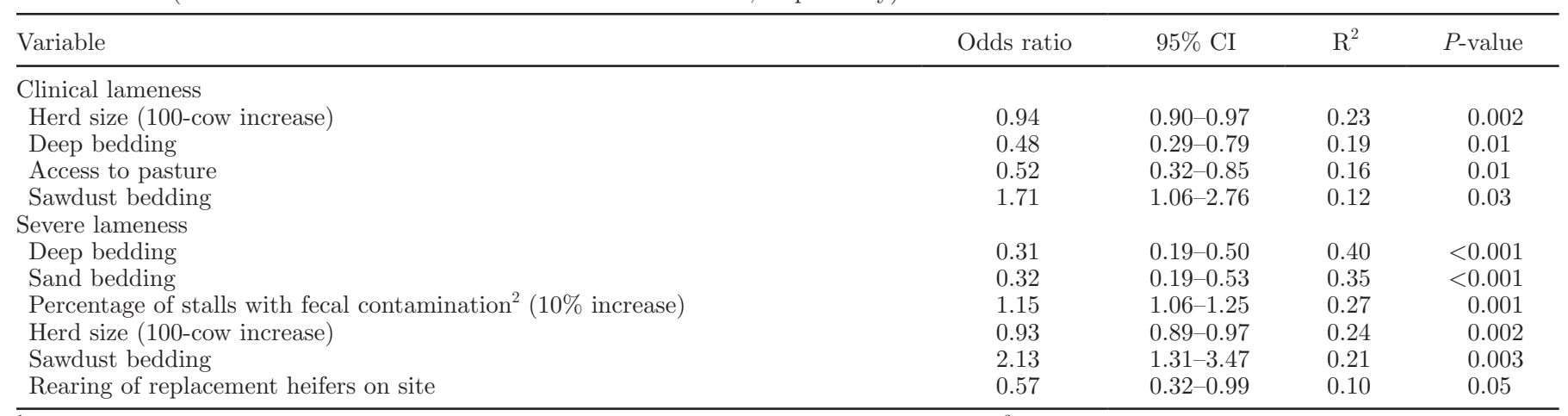

${ }^{1}$ Herd-level factors are sorted separately for clinical and severe lameness by descending $\mathrm{R}^{2}$. Parameter estimates were back-transformed and results are presented as odds ratios and $95 \%$ CI.

${ }^{2}$ Ten stalls/pen assessed before milking.

bedding, the model containing herd size and access to pasture explained $50 \%$ of the variation in clinical lameness $\left(\mathrm{R}^{2}=0.50\right.$; Table 3$)$.

One farm was discarded from the severe lameness analyses because it was an outlier and was an influential observation for most of the univariable models as well as the multivariable model (large negative residuals and Cook's distances). At the univariable level, severe lameness increased with the percentage of stalls with fecal contamination and with use of sawdust bedding, and decreased with deep bedding, sand bedding, herd size, and rearing of replacement heifers on site. Deep bedding and sand bedding were highly correlated ( $\mathrm{r}$ $=0.96 ; P<0.001)$ because all farms that used deep bedding also used sand (except for one that had dry manure), and none of the farms without deep bedding used sand. Only deep bedding was used in the multivariable model, because it had the larger $R^{2}$ at the univariable level. The percentage of stalls with fecal contamination was correlated with deep bedding ( $\mathrm{r}=$ $-0.65 ; P<0.001)$ and this variable was not retained in the final model containing deep bedding. The final model for severe lameness included deep bedding and herd size and explained $59 \%$ of the variation $\left(\mathrm{R}^{2}=\right.$ $0.59)$.

\section{California}

At the univariable level (Table 4), clinical lameness increased with the percentage of stalls with fecal contamination, and decreased with herd size, presence of rubber in the alley to the milking parlor, neck rail distance to the rear curb, water linear space per cow, and frequency of footbaths per week. The frequency of footbaths per week was correlated with the percentage of stalls with fecal contamination $(\mathrm{r}=-0.44 ; P=0.01)$, and was not retained in the model when the percentage of stalls with fecal contamination was accounted for. Herd size was correlated with water linear space per cow $(\mathrm{r}=0.43 ; P=0.01)$ and neck rail distance to the rear curb $(\mathrm{r}=0.49 ; P=0.002)$. When herd size was accounted for in the model, neither water linear space per cow nor neck rail distance to the rear curb was retained. The final model for clinical lameness included

Table 3. Multivariable associations of the logit-transformed proportion of clinical and severe lameness with herd-level factors in the northeastern United States $(\mathrm{n}=40$ and 39 farms for clinical and severe lameness, respectively) ${ }^{1}$

\begin{tabular}{lccccc}
\hline & $\begin{array}{c}\text { Parameter } \\
\text { estimate }\end{array}$ & $\mathrm{SE}$ & Odds ratio & $95 \% \mathrm{CI}$ & $P$-value \\
\hline Variable & & & & & \\
$\quad$ Clinical lameness & 1.01 & 0.17 & - & - & $<0.001$ \\
$\quad$ Intercept & -0.07 & 0.02 & 0.93 & $0.90-0.96$ & $<0.001$ \\
$\quad$ Herd size (100-cow increase) & -0.41 & 0.23 & 0.66 & $0.41-1.07$ & 0.09 \\
$\quad \begin{array}{l}\text { Deep bedding } \\
\text { Access to pasture }\end{array}$ & -0.44 & 0.22 & 0.64 & $0.41-1.00$ & 0.05 \\
$\quad$ Severe lameness & -1.78 & 0.16 & - & & \\
$\quad$ Intercept & -1.09 & 0.20 & 0.34 & $0.22-0.50$ & $<0.001$ \\
$\quad$ Deep bedding & -0.06 & 0.02 & 0.94 & $0.91-0.97$ & $<0.001$ \\
Herd size (100-cow increase) &
\end{tabular}

${ }^{1}$ Parameter estimates were back-transformed and results are presented as odds ratios and 95\% CI.

${ }^{2}$ Retained in the model as a confounder for access to pasture. 
Table 4. Univariable associations of the logit-transformed proportion of clinical lameness with herd-level factors in California $(\mathrm{n}=39 \text { farms })^{1}$

\begin{tabular}{|c|c|c|c|c|}
\hline Variable & Odds ratio & $95 \% \mathrm{CI}$ & $\mathrm{R}^{2}$ & $P$-value \\
\hline Herd size (100-cow increase) & 0.96 & $0.94-0.99$ & 0.23 & 0.002 \\
\hline Percentage of stalls with fecal contamination ${ }^{2}$ ( $10 \%$ increase) & 1.15 & $1.05-1.26$ & 0.22 & 0.003 \\
\hline Neck rail distance to the rear curb $^{3}$ (1-cm increase) & 0.97 & $0.95-0.99$ & 0.18 & 0.01 \\
\hline Water linear space per cow (1-cm increase) & 0.92 & $0.85-0.99$ & 0.13 & 0.03 \\
\hline Frequency of footbath per week (1-unit increase) & 0.90 & $0.81-0.99$ & 0.12 & 0.04 \\
\hline Frequency of manure removal in the pen per day (1-unit increase) & 0.72 & $0.53-0.97$ & 0.12 & 0.03 \\
\hline
\end{tabular}

${ }^{1}$ Herd-level factors were sorted separately for clinical and severe lameness by descending $\mathrm{R}^{2}$. Parameter estimates were back-transformed and results are presented as odds ratios and $95 \%$ CI.

${ }^{2}$ Ten stalls assessed before milking.

${ }^{3}$ Three to 7 stalls/pen.

herd size, percentage of stalls with fecal contamination, and presence of rubber in the alley to the milking parlor and explained $44 \%$ of the variation $\left(R^{2}=0.44\right.$; Table 5).

At the univariable level, severe lameness increased with the percentage of stalls with fecal contamination and decreased with frequency of manure removal in the pen per day. The final model for severe lameness included both the percentage of stalls with fecal contamination and the frequency of manure removal in the pen and explained $28 \%$ of the variation $\left(R^{2}=0.28\right)$.

\section{DISCUSSION}

This cross-sectional study provides insight into herdlevel risk factors for lameness in freestall herds in 2 regions of North America that differ in facility design and management, as well as in the prevalence of clinical and severe lameness.

\section{Northeastern United States}

On the NE farms, herd size was negatively associated with clinical and severe lameness. In contrast, some earlier studies considering herds outside of North America (Arkins, 1981; Alban, 1995; Whitaker et al.,
2000) reported an increased risk of lameness in larger herds. Alban (1995) suggested that because of more mechanization and less labor in large herds, farmers spent less time observing their cows, limiting the opportunity to identify and treat cows. However, these previous studies focused mostly on small herds, with diverse use of technology, mechanization, and labor. More recent studies in North America (Espejo and Endres, 2007; Barker et al., 2010), using larger herds in which differences in mechanization and technology were less likely to be related to herd size, did not find an effect of herd size on lameness. We suggest that the positive effects of larger herds in the current study are due to more professionalized management on many larger farms, including the availability of staff specifically responsible for lameness and hoof health. Further research is needed to document management factors related to this protective effect of herd size.

Several aspects of bedding were associated with clinical and severe lameness. Deep bedding was associated with decreased clinical and severe lameness and explained the most variation at the univariable level. Deep bedding remained significant in the final model for severe lameness, suggesting that deep bedding is important in preventing even these more severe cases.

Table 5. Multivariable associations of the logit-transformed proportion of clinical lameness with herd-level factors in California $(\mathrm{n}=39 \text { farms })^{1}$

\begin{tabular}{|c|c|c|c|c|c|}
\hline Variable & $\begin{array}{l}\text { Parameter } \\
\text { estimate }\end{array}$ & $\mathrm{SE}$ & Odds ratio & $95 \%$ CI & $P$-value \\
\hline \multicolumn{6}{|l|}{ Clinical lameness } \\
\hline Intercept & -0.69 & 0.30 & - & - & 0.03 \\
\hline Percentage of stalls with fecal contamination ${ }^{2}$ ( $10 \%$ increase) & 0.09 & 0.04 & 1.10 & $1.01-1.19$ & 0.03 \\
\hline Rubber in the alley to the parlor & -0.55 & 0.23 & 0.58 & $0.36-0.92$ & 0.02 \\
\hline \multicolumn{6}{|l|}{ Severe lameness } \\
\hline Frequency of manure removal in the pen per day (1-unit increase) & -0.30 & 0.14 & 0.74 & $0.56-0.98$ & 0.04 \\
\hline
\end{tabular}

${ }^{1}$ Parameter estimates were back-transformed and results are presented as odds ratios and 95\% CI.

${ }^{2}$ Ten stalls/pen assessed before milking. 
Cook et al. (2004) and Espejo et al. (2006) reported a lower prevalence of clinical lameness in farms with sand-bedded and deep-bedded stalls compared with farms with mattresses. Ito et al. (2010) reported a lower prevalence of severe lameness in farms with deep-bedded stalls, either sawdust- or sand-bedded, compared with farms with mattresses (covered with a small amount of various bedding materials). Deep bedding provides a more comfortable surface on which to lie down, increasing lying time and decreasing the amount of time cows spend standing on hard, wet surfaces, and thus decreasing the risk of lameness (reviewed by Cook and Nordlund, 2009). Deep bedding increases lying time, particularly for lame cows, suggesting that this surface helps lame cows recover and prevents the progression into severe lameness (Ito et al., 2010). Cook et al. (2008) found that use of mattresses increased standing time in lame cows.

Sand bedding was also associated with decreased severe lameness, whereas sawdust bedding was associated with increased clinical and severe lameness. As in other studies (Cook et al., 2004; Espejo et al., 2006), the bedding material was correlated with the quantity of bedding, such that most of the deep-bedded stalls had sand bedding and none used sawdust. Sawdust was a popular bedding material for mattresses, rubber mats, and waterbeds. Sawdust bedding did not remain in the final models containing deep bedding, suggesting that much of the variation in lameness associated with sawdust was accounted for in the models containing deep bedding. The variability in the bedding material is dependent on geographical factors, which makes it difficult to study the interaction between quantity of bedding and bedding material in regional observational studies. Further research is needed to study the interaction between deep bedding and different types of bedding, such as sand, dried manure, and sawdust.

The proportion of stalls with fecal contamination was associated with increased severe lameness at the univariable level. Deep-bedded stalls were less contaminated, and stall fecal contamination was not retained as a risk factor in the final model. This result suggests that the relationship between stall fecal contamination and severe lameness was partially confounded with the effect of deep bedding. The process of rising to a standing position is likely easier in deep-bedded stalls, particularly for lame cows (Cook and Nordlund, 2009); if cows can stand more easily, they may be less likely to defecate while lying down. However, it is also likely that maintaining the cleanliness of bedding (e.g., by adding fresh bedding more often) decreases the bacterial load in the stalls and therefore the risk of infectious diseases such as digital dermatitis.
Access to pasture during the dry period was associated with decreased clinical lameness. This result is in agreement with Haskell et al. (2006), who found that zero-grazing herds in Great Britain with either freestalls or straw yards had a prevalence of lameness more than twice that of herds with access to pasture in summer. Somers et al. (2003) found that cows in zero-grazing herds were more than twice as likely to have a hoof disorder, such as sole ulcers or dermatitis, compared with herds with access to pasture in summer. HernandezMendo et al. (2007) found that lame cows improved their gait within the first weeks of being moved from freestalls to pasture. Pasture is likely a more comfortable surface to stand upon than concrete, especially if the concrete flooring is covered with manure slurry and becomes slippery. Standing on pasture may also have a beneficial effect on hoof health. Pasture could also improve gait by reducing joint stiffness because it provides more friction than concrete floors covered with manure slurry (Gustafson, 1993; van der Tol et al., 2005) and more opportunities to exercise. Although exercise has been associated with better hoof health (Loberg et al., 2004), we are not aware of research that has directly assessed the effects of exercise on gait.

Rearing replacement heifers on site was associated with decreased severe lameness at the univariable level. Replacement heifers that are raised in another facility are usually reintroduced to the herd within weeks of calving. These heifers might have difficulties in transitioning to a new facility and a new social group, which can result in a decrease in stall use and an increase in standing time on concrete around calving time, when the hoof is at the highest risk of developing lesions (Webster, 2001; Tarlton et al., 2002). These heifers might not be accustomed to standing on concrete, because they are usually raised on a softer and less abrasive surface, such as dirt. Previous studies have shown that heifers that are moved from pasture to indoor housing on concrete within weeks of calving develop severe claw lesions (Kempson and Logue, 1993; Bergsten and Frank, 1996). Hirst et al. (2002) demonstrated that cows suffering lameness during the first lactation are more susceptible to lameness in subsequent lactations. Therefore, not rearing heifers on site could have a carryover effect throughout the productive life of cows and result in increased overall prevalence of lameness in the herd. Furthermore, the reintroduction of heifers could contribute to the introduction of infectious hoof diseases to the herd.

\section{California}

Herd size and the percentage of stalls with fecal contamination were the only 2 variables associated with 
lameness in both regions. In $\mathrm{CA}$, the percentage of stalls with fecal contamination was associated with both clinical and severe lameness and remained in the final models. The percentage of stalls with fecal contamination was correlated with the frequency of footbath per week, which in turn was associated with decreased clinical lameness at the univariable level. Most of the previous observational studies assessed presence of footbath, rather than frequency per week. Some studies found a beneficial effect (Arkins, 1981), whereas other found no effect (Espejo and Endres, 2007) or a detrimental effect (Chesterton et al., 1989; Amory et al., 2006). It is expected that well-managed footbaths decrease the prevalence of infectious diseases. If the main cause of lameness is not infectious, or the footbaths are not managed properly (e.g., the solution is too diluted or contaminated with manure), they could have no effect or negative effects. Moreover, Chesterton et al. (1989) suggested that farms with a high prevalence of lameness are more likely to use footbaths, which makes it difficult to meaningfully test this effect in an observational study. The product used in the footbath may also be important (Manske et al., 2002a), but this was not assessed in the current study. Frequency of footbath did not remain in the final models containing the percentage of stalls with fecal contamination, suggesting that much of the variation in lameness associated with the frequency of footbaths was accounted for in the models containing the percentage of stalls with fecal contamination. Caution is advised in interpreting this result because bedding hygiene could be both a cause and a consequence of lameness. Dirtier stalls will increase the risk of lameness because they will have larger load of infectious agents and will likely be more uncomfortable, decreasing stall use and increasing time standing on the wet concrete. On the other hand, lame cows are known to have difficulties in rising (Cook and Nordlund, 2009), and as a result these cows may more often defecate while lying down in the stall.

Similar to the NE farms, larger herd sizes had lower levels of clinical lameness. Larger herds also used less restrictive neck rails and provided more water space per cow. Less restrictive neck rails and more water space per cows were associated with decreased clinical lameness, although these factors did not remain in the final model including herd size. These results support the hypothesis that large herds are more likely to adopt management practices that are beneficial for lameness.

In agreement with Dippel et al. (2009), the more restrictive the neck rails, the higher the risk of lameness. In a crossover study, Bernardi et al. (2009) found that gait scores improved when the neck rail distance to the curb was increased and worsened when the neck rail distance was decreased. When the neck rail was less re- strictive, cows spent more time standing with all 4 feet on the stall bedding and less time standing on concrete.

Cows often compete for access to water (Coimbra et al., 2012), and this competition may be more intense in regions such $\mathrm{NE}$ and $\mathrm{CA}$, where cows can suffer from heat stress. Competition for water might result in lameness due to physical contact during agonistic interactions and due to an increase in time standing on concrete while waiting for the resource, particularly for primiparous or subordinate cows (Galindo and Broom, 2000). It is possible that the direct effect of lack of water space on lameness is only obvious in extreme cases. In other cases, the relationship between water space and lameness may be confounded by herd size; larger herds have more water space and also better lameness management.

Rubber in the alley to the milking parlor was associated with reduced lameness. Rubber floors provide more traction and more compressibility than concrete. As a result, cows slip less frequently, take longer strides, and increase walking speed when they walk on rubber compared with concrete (Phillips and Morris, 2001; Telezhenko and Bergsten, 2005; Rushen and de Passillé, 2006). Flower et al. (2007) found that improvements in locomotion when walking on rubber were particularly noticeable in lame cows. Cook and Nordlund (2009) suggested that the benefit of rubber on walking surfaces is 2-fold: less claw trauma and wear, which reduces the risk of new cases of lameness, and less concussion, which facilitates movement by cows. These results suggest that rubber provides a more secure footing and is a more comfortable surface to walk on, helping to prevent lameness and to facilitate recovery from cases that do occur.

The frequency of manure removal in the pen was associated with reduced severe lameness. Exposure of the hoof to manure has been associated with infectious (Somers et al., 2005) and hoof horn diseases (Gregory et al., 2006). Increased frequency of manure removal is supposed to keep the pen floor cleaner and dryer. Yet, frequent manure removal by automatic scrapers has been associated with increased lameness (Barker et al., 2007, 2010), possibly due to increased risk of dermatitis resulting from the wave of slurry created in front of the scraper (Somers et al., 2005) or by physical damage to the claw (Stefanowska et al., 2001). All farms in CA used water flushing to remove manure in the pen (sometimes combined with a skid steer), except for one that only used a skid steer. Manure removal with a skid steer or water flushing is mostly done while the cows are away for milking. These results suggest that frequent removal of manure could be beneficial for lameness, unless it is done using automated scrapers while cows are in the pen. 


\section{Study Design}

This was a cross-sectional study (risk factors and the outcome of interest were measured at the same time), making it impossible to draw strong conclusions about causality. This shortcoming applies mostly to management practices that are easy to modify and that are associated with increased lameness (certain practices can increase lameness but increased lameness can also lead to certain practices), but rarely to practices associated with decreased lameness or risk factors that are less flexible, such as facility design. Observational studies can identify associations between risk factors and the outcome of interest, but they cannot identify lack of association. Failure to find an association can be caused, for instance, by lack of variation in the predictor across the sampled farms.

Similarly to previous studies (Haskell et al., 2006; Espejo and Endres, 2007; Ito et al., 2010), the sampling strategy targeted high-producing cows. This is the cohort at highest risk for new cases of lameness, because it is composed mostly of multiparous cows in early or mid lactation, factors associated with lameness in previous research (Offer et al., 2000; Chapinal et al., 2010). This sampling strategy may overestimate the overall herd prevalence of lameness to some extent, assuming that some cases of lameness might resolve as lactation progresses if properly treated. However, lameness is a long-term event and the lack of homogeneity of most high-producing groups (some included primiparous cows and a wide range of DIM) might have helped reduce the bias. The target sampling also provided advantages. High-producing cows are the cohort in which the effects on lameness of inappropriate facility design and management (even in other stages of the cycle, such as the periparturient period) are more likely to surface, and therefore the cohort where the strongest association between risk factors and lameness are likely to be found. The high-producing group may thus serve as sentinels for the detection of risk factors for lameness elsewhere on the farm.

In agreement with similar on-farm lameness surveys (Amory et al., 2006; Espejo and Endres, 2007; Dippel et al., 2009), we defined lameness based on gait rather than hoof health (Somers et al., 2003; Barker et al., 2009; Cramer et al., 2009). Although we observed good correlation between certain lesions, such as sole ulcers and gait impairment (Flower and Weary, 2006; Chapinal et al., 2009), not all hoof lesions result in gait alteration, and not all cases of lameness are associated with a visible hoof lesion (Manske et al., 2002b). Gait can be assessed daily on farm as cows walk from the pen to the milking parlor, whereas hoof trimming is required to assess lesions. We suggest that the prevalence of animals with impaired gait is a better parameter than prevalence of hoof lesions to study the effect of herd-level factors on lameness, and it is a better indicator to evaluate the application of strategic prevention plans.

\section{CONCLUSIONS}

Management and facility design differed between $\mathrm{NE}$ and CA, but some risk factors for lameness were common to both regions, including fecal contamination of the bedding and smaller herd size. Several aspects of the bedding were associated with lameness in NE, particularly the presence of deep bedding, which was associated with both decreased clinical and severe lameness. Access to pasture during the dry period and rearing heifers on site were associated with decreased clinical and severe lameness, respectively. In CA, presence of rubber in the alley to the milking parlor, less restrictive neck rail placements, more water space per cow, and frequent footbaths were associated with decreased clinical lameness, and frequent removal of manure in the pen was associated with decreased severe lameness. Most of the herd-level risk factors associated with lameness in the current study can be modified to prevent lameness. These results provide a basis for formulating science-based, region-specific recommendations for reducing lameness on commercial farms.

\section{ACKNOWLEDGMENTS}

We thank the staff and students in the UBC Animal Welfare Program (Vancouver, BC, Canada) for the many useful discussions that took place throughout this project. We especially thank Kiyomi Ito, Stephanie Gable, and Mercedes Vazquez-Anon from Novus International Inc. (St. Charles, MO) for their support in making this project successful. This project was funded by Novus International Inc. The UBC Animal Welfare Program is funded through NSERC's Industrial Research Chair program, with industry contributions from the Dairy Farmers of Canada (Ottawa, ON, Canada), Westgen Endowment Fund (Milner, BC, Canada), Pfizer Animal Health (Kirkland, QC, Canada), BC Cattle Industry Development Fund (Kamloops, BC, Canada), the BC Milk Producers (Burnaby, BC, Canada), BC Dairy Foundation (Burnaby, BC, Canada), BC Dairy Industry Research and Education Fund (Abbotsford, BC, Canada), and Alberta Milk (Edmonton, AB, Canada).

\section{REFERENCES}

Alban, L. 1995. Lameness in Danish dairy cows: Frequency and possible risk factors. Prev. Vet. Med. 22:213-225.

Amory, J. R., P. Kloosterman, Z. E. Barker, J. L. Wright, R. W. Blowey, and L. E. Green. 2006. Risk factors for reduced locomo- 
tion in dairy cattle on nineteen farms in the Netherlands. J. Dairy Sci. 89:1509-1515.

Arkins, S. 1981. Lameness in dairy cows. Ir. Vet. J. 35:135-140.

Barker, Z. E., J. R. Amory, J. L. Wright, R. W. Blowey, and L. E. Green. 2007. Management factors associated with impaired locomotion in dairy cows in England and Wales. J. Dairy Sci 90:3270-3277.

Barker, Z. E., J. R. Amory, J. L. Wright, S. A. Mason, R. W. Blowey, and L. E. Green. 2009. Risk factors for the increased rates of sole ulcers, white line disease, and digital dermatitis in dairy cattle from twenty-seven farms in England and Wales. J. Dairy Sci. 92:1971-1978.

Barker, Z. E., K. A. Leach, H. R. Whay, N. J. Bell, and D. C. J. Main. 2010. Assessment of lameness prevalence and associated risk factors in dairy herds in England and Wales. J. Dairy Sci. 93:932-941.

Bergsten, C., and B. Frank. 1996. Sole hemorrhages in tied primiparous cows as an indicator of periparturient laminitis: Effects of diet, flooring and season. Acta Vet. Scand. 37:383-394.

Bernardi, F., J. Fregonosi, D. M. Veira, C. Winkler, M. A. G. von Keyserlingk, and D. M. Weary. 2009. The stall-design paradox: Neck rails increase lameness but improve udder and stall hygiene. J. Dairy Sci. 92:3074-3080.

Canadian Council on Animal Care (CCAC). 2009. CCAC guidelines on: the care and use of farm animals in research, teaching and testing. CCAC, Ottawa, ON, Canada.

Chapinal, N., A. M. de Passillé, D. M. Weary, M. A. G. von Keyserlingk, and J. Rushen. 2009. Using gait score, walking speed, and lying behavior to detect hoof lesions in dairy cows. J. Dairy Sci. 92:4365-4374.

Chapinal, N., C. Goldhawk, A. M. de Passillé, M. A. G. von Keyserlingk, D. M. Weary, and J. Rushen. 2010. Overnight access to pasture does not reduce milk production or feed intake in dairy cattle. Livest. Sci. 129:104-110.

Chesterton, R. N., U. Pfeiffer, R. S. Morris, and C. M. Tanner. 1989. Environmental and behavioural factors affecting the prevention of foot lameness in New Zealand dairy herds. A case control study. N. Z. Vet. J. 37:135-142.

Coimbra, P. A. D., L. C. P. Machado Filho, and M. J. Hötzel. 2012. Effects of social dominance, water trough location and shade availability on drinking behaviour of cows on pasture. Appl. Anim. Behav. Sci. 139:175-182.

Cook, N. B. 2003. Prevalence of lameness among dairy cattle in Wisconsin as a function of housing type and stall surface. J. Am. Vet. Med. Assoc. 223:1324-1328

Cook, N. B., T. B. Bennett, and K. V. Nordlund. 2004. Effect of free stall surface on daily activity patterns in dairy cows with relevance to lameness prevalence. J. Dairy Sci. 87:2912-2922.

Cook, N. B., M. J. Marin, R. L. Mentink, T. B. Bennett, and M. J. Schaefer. 2008. Comfort zone-design free stalls: Do they influence the stall use behavior of lame cows? J. Dairy Sci. 91:4673-4678.

Cook, N. B., and K. V. Nordlund. 2009. The influence of the environment on dairy cow behaviour, claw health and herd lameness dynamics. Vet. J. 179:360-369.

Cox, D. R., and E. J. Snell. 1970. Analysis of Binary Data. 2nd ed. Chapman and Hall, London, UK.

Cramer, G., K. D. Lissemore, C. L. Guard, K. E. Leslie, and D. F. Kelton. 2009. Herd-level risk factors for seven different foot lesions in Ontario Holstein cattle housed in tie stalls or free stalls. J. Dairy Sci. 92:1404-1411.

Dippel, S., M. Dolezal, C. Brenninkmeyer, J. Brinkmann, S. March, U. Knierim, and C. Winckler. 2009. Risk factors for lameness in freestall housed dairy cows across two breeds, farming systems, and countries. J. Dairy Sci. 92:5476-5486.

Dohoo, I., W. Martin, and H. Stryhn. 2009. Veterinary Epidemiologic Research. 2nd ed. VER Inc., Charlottetown, Prince Edward Island, Canada.

Espejo, L. A., and M. I. Endres. 2007. Herd-level risk factors for lameness in high-producing Holstein cows housed in freestall barns. J. Dairy Sci. 90:306-314.
Espejo, L. A., M. I. Endres, and J. A. Salfer. 2006. Prevalence of lameness in high-producing Holstein cows housed in freestall barns in Minnesota. J. Dairy Sci. 89:3052-3058.

Flower, F. C., A. M. de Passillé, D. M. Weary, D. J. Sanderson, and J. Rushen. 2007. Softer, higher-friction flooring improves gait of cows with and without sole ulcers. J. Dairy Sci. 90:1235-1242.

Flower, F. C., and D. M. Weary. 2006. Effect of hoof pathologies on subjective assessments of dairy cow gait. J. Dairy Sci. 89:139-146.

Galindo, F., and D. M. Broom. 2000. The relationships between social behaviour of dairy cows and the occurrence of lameness in three herds. Res. Vet. Sci. 69:75-79.

Gregory, N., L. Craggs, N. Hobson, and C. Krogh. 2006. Softening of cattle hoof soles and swelling of heel horn by environmental agents. Food Chem. Toxicol. 44:1223-1227.

Gustafson, G. M. 1993. Effects of daily exercise on the health of tied dairy cows. Prev. Vet. Med. 17:209-223.

Haskell, M. J., L. J. Rennie, V. A. Bowell, M. J. Bell, and A. B. Lawrence. 2006. Housing system, milk production, and zerograzing effects on lameness and leg injury in dairy cows. J. Dairy Sci. 89:4259-4266.

Hernandez-Mendo, O., M. A. von Keyserlingk, D. M. Veira, and D. M. Weary. 2007. Effects of pasture on lameness in dairy cows. J. Dairy Sci. 90:1209-1214.

Hirst, W. M., R. D. Murray, W. R. Ward, and N. P. French. 2002. A mixed-effects time-to-event analysis of the relationship between first-lactation lameness and subsequent lameness in dairy cows in the UK. Prev. Vet. Med. 54:191-201.

Ito, K., M. A. G. von Keyserlingk, S. J. LeBlanc, and D. M. Weary. 2010. Lying behavior as an indicator of lameness in dairy cows. J. Dairy Sci. 93:3553-3560.

Kempson, S. A., and D. N. Logue. 1993. Ultrastructural observations of hoof horn from dairy cows: Changes in the white line during the first lactation. Vet. Rec. 132:524-527.

Loberg, J., E. Telezhenko, C. Bergsten, and L. Lidfors. 2004. Behaviour and claw health in tied cows with varying access to exercise in an outdoor paddock. Appl. Anim. Behav. Sci. 89:1-16.

Manske, T., J. Hultgren, and C. Bergsten. 2002a. Topical treatment of digital dermatitis associated with severe heel-horn erosion in a Swedish dairy herd. Prev. Vet. Med. 53:215-231.

Manske, T., J. Hultgren, and C. Bergsten. 2002b. Prevalence and interrelationships of hoof lesions and lameness in Swedish dairy cows. Prev. Vet. Med. 54:247-263.

Offer, J. E., D. McNulty, and D. N. Logue. 2000. Observations of lameness, hoof conformation and development of lesions in dairy cattle over four lactations. Vet. Rec. 147:105-109.

Phillips, C. J. C., and I. D. Morris. 2001. The locomotion of dairy cows on floor surfaces with different frictional properties. J. Dairy Sci. 84:623-628.

Rushen, J., and A. M. de Passillé. 2006. Effects of roughness and compressibility of flooring on cow locomotion. J. Dairy Sci. 89:29652972.

Sogstad, A. M., T. Fjeldaas, O. Osteras, and K. P. Forshell. 2005. Prevalence of claw lesions in Norwegian dairy cattle housed in tie stalls and free stalls. Prev. Vet. Med. 70:191-209.

Somers, J. G., K. Frankena, E. N. Noordhuizen-Stassen, and J. H. Metz. 2003. Prevalence of claw disorders in Dutch dairy cows exposed to several floor systems. J. Dairy Sci. 86:2082-2093.

Somers, J. G. C. J., K. Frankena, E. N. Noordhuizen-Stassen, and J. H. M. Metz. 2005. Risk factors for interdigital dermatitis and heel erosion in dairy cows kept in cubicle housing in The Netherlands. Prev. Vet. Med. 71:23-34.

Stefanowska, J., D. Swierstra, C. R. Braam, and M. M. W. B. Hendriks. 2001. Cow behaviour on a new grooved floor in comparison with slatted floor, taking claw health and floor properties into account. Appl. Anim. Behav. Sci. 71:87-103.

Tarlton, J. F., D. E. Holah, K. M. Evans, S. Jones, G. R. Pearson, and A. J. Webster. 2002. Biomechanical and histopathological changes in the support structures of bovine hooves around the time of first calving. Vet. J. 163:196-204.

Telezhenko, E., and C. Bergsten. 2005. Influence of floor type on the locomotion of dairy cows. Appl. Anim. Behav. Sci. 93:183-197. 
van der Tol, P. P. J., J. H. M. Metz, E. N. Noordhuizen-Stassen, W. Back, C. R. Braam, and W. A. Weijs. 2005. Frictional forces required for unrestrained locomotion in dairy cattle. J. Dairy Sci. $88: 615-624$.

von Keyserlingk, M. A. G., A. Barrientos, K. Ito, E. Galo, and D. M. Weary. 2012. Benchmarking cow comfort on North American freestall dairies: Lameness, leg injuries, lying time, facility design and management, for high producing Holstein dairy cows. J. Dairy Sci. 95:7399-7408. http://dx.doi.org/10.3168/jds.2012-5807.

Webster, A. J. F. 2001. Effects of housing and two forage diets on the development of claw horn lesions in dairy cows at first calving and in first lactation. Vet. J. 162:56-65.

Whitaker, D. A., J. M. Kelly, and S. Smith. 2000. Disposal and disease rates in 340 British dairy herds. Vet. Rec. 146:363-367. 